\title{
El mercado de esclavos en la ciudad de Lima desde el Mercurio Peruano, 1827-1832
}

\section{The Slavery Market in the City of Lima from the Mercurio Peruano, 1827 - 1832}

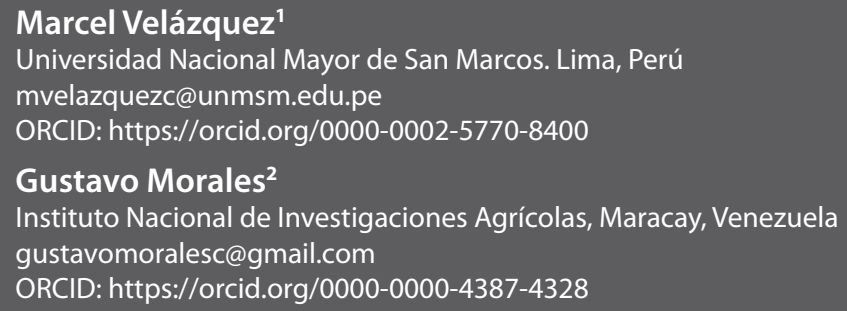

Citar como: Velázquez, M. y Morales, G. (2021). El mercado de esclavos en la ciudad de Lima desde el Mercurio Peruano, 1827-1832. Desde el Sur, 13(3), e0028

\section{RESUMEN}

Esta investigación analiza las variables de edad, sexo, precio y oficios en un corpus de avisos comerciales relacionados con el mercado de esclavos en Lima, publicados en el diario Mercurio Peruano (agosto de 1827-diciembre de 1832). El objetivo de este trabajo es conocer las características de la oferta y la demanda de esclavos en la capital del Perú, en unos años en los cuales ya no había reproducción social interna de la esclavitud ni ingreso de nuevos esclavos a Lima mediante la trata internacional. Los avisos comerciales de esclavos contribuyen a iluminar aspectos de la vida laboral de los esclavos y tensiones de la sociedad del momento, pues la esclavitud formaba parte de la

1 Doctor en Literatura Latinoamericana por la Universidad Andina Simón Bolívar (Quito). Diplomado en Estudios de Género por la Pontificia Universidad Católica del Perú. Profesor principal en la Facultad de Letras y Ciencias Humanas de la Universidad Nacional Mayor de San Marcos. Investigador Renacyt.

2 Médico veterinario, con posgrado en Patología Animal Tropical (Alfort, Francia), doctor por la Universidad Pierre et Marie Curie, Paris VI, ex profesor titular de la Universidad de Los Andes, investigador jubilado del Instituto Nacional de Investigaciones Agropecuarias, Premio Conicit 1988 y mención honorífica Fundacite Aragua. Autor de tres libros sobre métodos estadísticos no paramétricos, dos libros de parasitología, 130 artículos de investigación publicados en revistas arbitradas y una treintena en divulgativas arbitradas. Ha participado como conferencista en eventos nacionales e internacionales, revisor científico en publicaciones periódicas. 
experiencia cotidiana de unos lectores que, por un lado, defendían principios formales de la libertad e igualdad entre los ciudadanos, y, por el otro, ratificaban el orden tradicional de la desigualdad esencial entre los hombres. En términos metodológicos, este artículo combina los métodos estadísticos y el análisis histórico-discursivo.

\section{PALABRAS CLAVE}

Esclavos, Lima, mercado, prensa, precios

\section{ABSTRACT}

This paper analyzes the variables of age, sex, cost, and occupation, within a set of commercial advertisements of slave trade in Lima published in the journal Mercurio Peruano (August 1827- December 1832). The study aims to delve into the dynamics and characteristics of slave trade's supply and demand in the capital of Peru, in years when there was no internal social reproduction of slaves and international slave trade didn 't provide any more slaves in Lima. Commercial advertisements published within the pages of this republican newspaper shed light about labour life of slaves and the social contradictions of the time, since slavery was familiar to readers who felt these notices as part of their everyday life (hence, saw slavery and essential human inequality as natural), at the same time that they would defend the tenets of freedom and equality between the citizens. In terms of methodology, this paper combines statistical methods with historical and discursive analysis.

\section{KEYWORDS}

Slaves, Lima, market, press, prices

\section{Introducción}

La esclavitud en el Perú durante el siglo XIX ha sido objeto de múltiples investigaciones históricas. Agentes de su propia libertad (1993) de Carlos Aguirre postula cuatro formas básicas de resistencia desplegadas por los esclavos: el conflicto legal, las estrategias para acceder a la liber$\operatorname{tad}^{3}$, el cimarronaje y las formas violentas de lucha. Se estudia la dinámica 
combinada de estas modalidades dentro de un esquema matriz de resistencia y adaptación. Por ello, la necesidad de organizarse en una rebelión colectiva contra la esclavitud no fue necesaria (1993, pp. 15-26). Por su parte, Christine Hünefeldt es la primera en estudiar la problemática de la mujer esclava e introducir la variable de género en sus múltiples análisis. Paying the price of freedom (1994) es la síntesis y la culminación de su prolongada exploración previa en las redes familiares, sociales y económicas de los esclavos. La interacción sociocultural de amos y esclavos generó la renegociación de las posiciones y el socavamiento de la esclavitud, como la apropiación del discurso religioso/moral para usar las instituciones cristianas — como el matrimonio-, y el intenso y acelerado mestizaje (1994, pp. 199-200). Finalmente, El Decreto de Huancayo. La abolición de la esclavitud en el Perú (2004) de Jean Pierre Tardieu ${ }^{4}$ realiza un recorrido diacrónico por la legislación republicana y los discursos de la élite que desemboca en el Decreto de Huancayo, que establece la libertad de los esclavos. Es una presentación meticulosa que logra correlacionar los vaivenes legislativos con la presión social de los hacendados y las ideas políticas hegemónicas.

En este artículo realizaremos un análisis a profundidad de un corpus de avisos comerciales de esclavos en la prensa republicana, como una fuente de la vida social en Lima y de los discursos sobre la esclavitud. Este artículo postula como hipótesis que los avisos comerciales constituyen micronarraciones de la vida de un esclavizado, y ofrecen valiosa información social sobre el mercado urbano de esclavos. Por otra parte, organizan y legitiman el discurso del sujeto esclavista y exponen en el espacio público los límites de la promesa republicana.

\section{Contexto histórico. Características del Mercurio Peruano}

Desde 1817, por influencia política y militar de Inglaterra, el tráfico de esclavos estaba abolido en España y sus colonias, es decir, no se podía ingresar nuevos esclavos por el puerto del Callao. Debido a su independencia política (28 de julio de 1821), el diseño legal de la esclavitud en el Perú sufrió importantes cambios. El 12 de agosto de 1821, San Martín estableció que todo hijo de esclava nacido después de la Independencia era libre. Así se impedía la reproducción de la esclavitud en el interior de la sociedad peruana. Como complemento del decreto de la libertad

4 Este importante investigador francés ha publicado otros dos libros que abordan aspectos de la esclavitud en el Perú del siglo XVI y XVII. Desde una perspectiva histórica institucional, Los negros y la Iglesia en el Perú (1997) ofrece una gran cantidad de información de primer orden sobre la Iglesia como poder esclavista, medio de control social, y agente de protección de los negros en el Perú. Desde la perspectiva de las historias regionales, El negro en el Cuzco (1998) tiene el mérito de quebrar uno de los tópicos sobre el tema al analizar la presencia de la comunidad negra en un espacio andino. 
de vientres, se promulgó el decreto del 24 de noviembre del mismo año. Esta norma permitió a los amos seguir en control de los esclavos nacidos después de la independencia política hasta que cumplieran 20 años, en el caso de las mujeres, y 24 en el caso de los varones.

Ya bajo el régimen de Bolívar se promulgó el denominado «Reglamento interior de las haciendas de la costa» (14 de octubre de 1825), que legitimaba nuevamente el castigo físico y protegía el afán de dominio de los amos sobre los esclavos y sus hijos. Así,

en las primeras décadas republicanas, la esclavitud (institución jurídica, social y económica) fue parte de la vida privada y la experiencia material del limeño. El mercado de esclavos y sus avatares dinamizan comercialmente a la prensa del periodo mediante el anuncio de compras, ventas e incluso permutas de esclavos; las denuncias sobre esclavos fugados y las gratificaciones ofrecidas por información sobre su paradero. Todo ello presupone la configuración del esclavo como una mercancía más del incipiente mercado de bienes y servicios (Velázquez, 2013, p. 112).

En este marco de pugna entre diversas fuerzas sociales, los intereses de los hacendados limeños por preservar la esclavitud se imponían sobre las acciones de los esclavos para desintegrarla. Por su parte, el mercado de esclavos quedó reducido, pues no podía aumentar la oferta; sin embargo, se siguieron comprando y vendiendo esclavos, incluso nacidos después del 28 de julio de 1821, como demostró con un caso Magdalena Chocano (2019, p. 130).

Por otra parte, hay que considerar que hacia 1813 en la ciudad de Lima se censaron 12263 esclavos de una población de 56284 habitantes en la ciudad, es decir, 21,8\%; este porcentaje descendió en 1820 al 13,42\% de la población (8589 esclavos) y en 1836 al 10,4\% (4791 esclavos) (Velázquez, 2005, p. 49). Aunque las fuentes de los dos últimos registros es la estadística de Córdova y Urrutia (1839) y esta no es muy precisa, es evidente el acentuado descenso de la población esclava tanto en términos porcentuales como en términos reales durante esos años. Finalmente, se conservaba la clásica distinción entre esclavo bozal (nacido en tierras africanas y con dificultades para hablar el español) y el esclavo criollo, a veces mestizo, que había nacido en tierras americanas y que dominaba la lengua española.

La tesis de licenciatura de Víctor Haro (2017) examina el precio de los esclavos durante el periodo virreinal a través del análisis de la información registrada en los protocolos notariales de la época. Es importante notar que, durante el Virreinato, la compra de un esclavo representaba una inversión considerable: «Un esclavo podía llegar a costar como una casa 
pequeña, una fanega de tierra, e incluso como una embarcación» (Haro, 2017 , p. 64). El elevado precio de un solo esclavo da cuenta de la importancia que tenía esta población como mano de obra durante el periodo mencionado.

Mientras que el valor de los esclavos era considerable, se comprueba que existía una diferencia de precio favorable a los primeros entre los esclavos bozales y los no-bozales (Haro, 2017, p. 63). Esta diferencia es especialmente acentuada durante el siglo XVII, en el contexto de un flujo constante de esclavos africanos comercializados por los portugueses. Dicha situación se transforma durante los últimos 40 años del siglo XVIII: la brecha de precio entre bozales y no-bozales se acorta, a la vez que se aprecia un descenso general en el costo de los esclavos. Estas tendencias se agudizaron en el siglo XIX, pues Inglaterra impulsó la prohibición de la trata de esclavos a nivel internacional y la normativa peruana también tuvo como efecto la reducción de la oferta. Por todo ello, después de la consolidación de la Independencia (1824), hubo muy pocos esclavos bozales ofertados en el mercado de Lima y el precio de los esclavos descendió significativamente.

Respecto de la evolución del precio de los esclavos, la tesis de Haro es relevante para este artículo, pues establece un valor promedio de las transacciones económicas de compraventa durante dos décadas 1800-1819; así, el promedio de varones esclavos no-bozales fue de 334,5 pesos y el de mujeres esclavas no-bozales fue de 337 pesos (2017, pp. 71-72). Estos valores nos permitirán establecer una tendencia con los valores de ofertas de compra y de venta que se han encontrado en esta investigación en el lapso posterior de 1827-1832.

El Mercurio Peruano 5 (agosto de 1827-marzo de 1834) significó la primera experiencia sostenida en el tiempo de un diario en el Perú republicano, dirigido por la élite letrada. El 24 de julio de 1827 se publicó su Prospecto; el 1 de agosto, el primer número. Tenía periodicidad diaria, excepto los días festivos (domingos y feriados); se vendía a real el número suelto, la suscripción era de dos pesos mensuales pagados con anticipación, tenía cuatro páginas, divididas cada una en dos columnas y se imprimía en la Imprenta de la Libertad de José Masías. Su tamaño era mediano y su formato de aproximadamente $15 \mathrm{~cm}$ por $24 \mathrm{~cm}$. El prospecto señalaba explícitamente el campo de la política y el campo de la literatura como los ámbitos de interés privilegiados. 


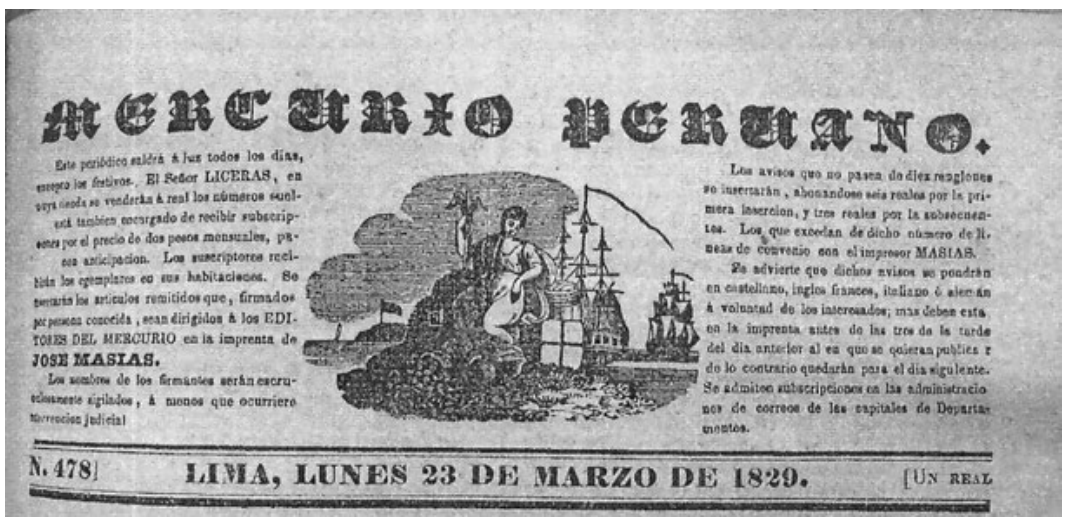

FIGURA 1. Portada del Mercurio Peruano del 23 de marzo de 1829

Nota. Tomado de [Portada]. (23 de marzo de 1829). Mercurio Peruano.

Esta publicación posee tres características centrales: a pesar del nombre, constituía una expresión de la prensa de Lima, es decir, se escribía, distribuía y leía, fundamentalmente, en la capital del Perú; en su dimensión ideológico-política estaba asociado a los conservadores, los hombres del orden que defendían un Ejecutivo fuerte y preeminente sobre el Legislativo: uno de sus redactores principales era José María de Pando; ofrecía textos sobre aspectos político-constitucionales y mucha información comercial y marítima de la ciudad de Lima. Se impuso como tarea crear una corriente de opinión e influir mediante artículos razonados en las decisiones de gobierno de los presidentes, el general La Mar (1827-1829) y el general Gamarra (1829-1833).

Pese a la importancia de este diario, no hay estudios exhaustivos sobre él. Raúl Porras Barrenechea señala que este periódico no brindaba información de los hechos políticos, sino comentarios e interpretaciones de estos; resalta la «inflexible lógica y elegancia formal» $(1970$, p. 23) de José María de Pando y destaca que era el diario «serio y generalmente leído: El Comercio de aquella época y sobre todo en el gobierno de Gamarra» (1970, p. 24). Por su parte, Jorge Basadre señala escuetamente que «el segundo Mercurio Peruano fue fundado por José María de Pando, llegó a ser redactado durante un tiempo por José Antolín Rodolfo y Felipe Pardo y duró hasta 1834 para revivir, por corto tiempo, en 1839 y 1840, muriendo a causa de la competencia de El Comercio» (1983, II, p. 287).

La estructura del periódico estaba conformada por seis secciones: «Exterior», «Interior», «Variedades», «Remitidos», «Marítima» y «Avisos del día». En la primera sección, se consignaba artículos sobre países extranjeros, principalmente americanos o europeos tomados de otros periódicos como El Patriota de Guayaquil, El Reconciliador Bogotano, El 
Constitucional de Bogotá, Boston Daily Advertiser, El Verdadero Liberal de Chile, El Reconciliador de Caracas, La Crónica de Buenos-Ayres, El Conductor de Bogotá, El Mercurio de Valparaíso, El Cóndor de Bolivia, La Gaceta de Colombia y Aurora de Chile, entre otros. En la sección «Interior» se resumía las sesiones del Congreso y las principales disposiciones legislativas. En «Variedades» se incluían textos literarios (sonetos y letrillas, principalmente), anécdotas ejemplares y textos varios de economía y ciencia (geometría, historia, química, entre otros). «Remitidos» contenía las cartas y los artículos de opinión de los lectores. «Marítima» presentaba la información sobre las entradas y salidas de embarcaciones marítimas de los diversos puertos, principalmente del Callao. También se presentaba al final una sección de avisos que normalmente se referían a la oferta de servicios de diversa índole y a la compra, venta y alquiler de diversos bienes y mercancías, entre ellos esclavos.

La amplia mayoría de avisos sobre esclavos se insertaba en la sección «Avisos del día». En ellos se ofrecía una variada gama de bienes y servicios. Por ejemplo, se informa sobre las fragatas disponibles para transportar pasajeros y carga, a destinos como Huanchaco, Pisco, Guayaquil; los servicios de una escuela de primeras letras, de un médico o de una modista costurera francesa; el arriendo de chacras, el traslado o venta de locales comerciales, las funciones de teatro (comedias, tragedias y sainetes), venta de inmuebles, libros, otras publicaciones periódicas, artículos caseros, artículos de labranza, calesas, carretas, caballos, mulas, cigarros, pipas de vino, rifas; la llegada y salida del correo con cartas y mercancías; entre muchos otros.

Los 249 avisos singulares sobre compra, venta ${ }^{6}$, alquiler y permuta de esclavos publicados durante agosto de 1827 y diciembre de 1832 en el diario Mercurio Peruano son el objeto central de esta investigación. No se ha considerado el año 1833 ni los tres primeros meses de 1834 porque no se han podido hallar en Lima colecciones completas de ese lapso. Los avisos comerciales poseían 10 renglones como máximo; su publicación costaba 6 reales la primera vez y, si se repetía en otro número, 3 reales. Cabía la posibilidad de obtener avisos más extensos en acuerdo con los editores.

Como es bien sabido, los esclavos no concitaron gran atención en las formas letradas de representación de las élites decimonónicas, pero en estos avisos ellos ocupan el centro de la representación. Así, además del

6 Estos avisos constituyen una etapa anterior a la operación de compraventa del esclavo, pues son una oferta de compra o de venta del mismo y por eso hay dos precios distintos, en función del interés de quien publica el aviso y lo que desea obtener con la venta o pagar con la compra. 
precio, conocemos rasgos centrales de la propia vida del esclavo (edad, lugar de procedencia, apariencia, habilidades laborales, etc.). Paradójicamente, como ha demostrado Velázquez (2013, p. 115), cuando se quiere recuperar un esclavo fugado o perdido, los esfuerzos de descripción son más detallados e incluyen aspectos negativos, a diferencia de cuando se quiere vender uno. En el caso de este corpus de avisos del Mercurio Peruano, esta generalización se verifica con el aviso del 19 de agosto de 1831, respecto de un esclavo fugado: «Eusebio (25), al andar alza los hombros, saca los codos atrás, cuando se agita le silva el pecho, padece de tos. Nació en Moquegua». La amplia y detallada información personal que se consigna sobre el cuerpo contrasta con las fórmulas comerciales más escuetas en los avisos de compra y venta.

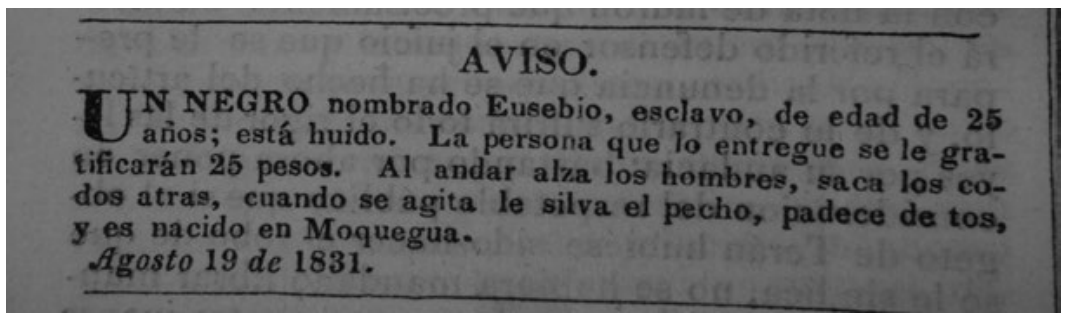

FIGURA 2. Aviso de fuga de esclavo

Nota. Tomado de "Aviso". (19 de agosto de 1831). Mercurio Peruano, 1178, p. 4.

\section{Materiales y métodos}

Para la realización de este trabajo se utilizó como fuente de información a los avisos comerciales periodísticos, publicados en el diario Mercurio Peruano, referidos a la compra, la venta y el alquiler de esclavos y esclavas, durante el lapso de agosto de 1827 a diciembre de 1832.

\section{Análisis de la información}

En el caso de la información cualitativa se elaboraron gráficos de torta y de barras, y para la información cuantitativa, específicamente la referida a la distribución de la frecuencia de edades, se empleó el histograma y el diagrama de cajas.

Previo a la realización de los análisis estadísticos inferenciales y gráficas, se establecieron las estadísticas descriptivas referentes a la cantidad de esclavos ofertados durante el lapso 1827-1832, discriminados por transacción comercial y sexo (Balzarini et al., 2008, pp. 45-50).

Para el análisis estadístico de los datos, se recurrió a métodos no paramétricos, debido a que estos no tenían una distribución normal, además de ser los más recomendados con muestras desbalanceadas, 
pequeñas o con presencia de datos anómalos y con datos de observación (Morales y Pino, 2009, pp. 13-14; Siegel y Castellán, 1995, pp. 55-58).

Para comparar entre las ofertas de esclavos en alquiler, venta o compra entre los años 1827 a 1832, se procedió previamente a agrupar los datos por mes, o sea que cada mes representa todas las operaciones realizadas por cinco años y por consiguiente cada categoría de clasificación consta de 12 datos contentivos de la sumatoria mensual de 323 registros sobre el número de esclavos ofertados, que a su vez estaban contenidos en 249 avisos de prensa y discriminados de acuerdo con el tipo de transacción comercial. El interés era determinar si existían o no diferencias estadísticamente significativas entre los tres tipos básicos de transacciones comerciales (alquiler, venta o compra), las cuales fueron consideradas como categorías de clasificación para el lapso analizado. En este caso se recurrió al análisis de varianza de una clasificación por rangos de una vía para varias muestras independientes de Kruskal-Wallis, y, como prueba para la separación de medianas, usamos la mínima diferencia significativa a un nivel del 5\%, tal como lo indica Morales (2009, pp. 65-72).

La comparación entre los precios de comercialización en relación con el sexo, entre edades y sexo, edad y operación comercial, precio de los esclavos y sexo, fueron realizadas mediante la prueba de una clasificación por rangos para dos muestras independientes de $U$ de Mann y Whitney (Morales y Pino, 2009, pp. 52-64). Para evaluar la posible asociación entre el sexo y la operación comercial (alquiler, compra o venta) se empleó la prueba de ji-cuadrado (Morales y Pino, 2009, pp. 33-44), y cuando se encontró las existencias de diferencias estadísticamente significativas en tablas de NxK, se recurrió a la prueba de la comparación de proporciones 2 a 2 (Balzarini et al., 2008, pp. 78), como vía para la separación de los porcentajes a posteriori. La selección de las pruebas estadísticas se hizo según indicaciones de Morales y Pino (2009, pp. 17-19) y Siegel y Castellan (1995, pp. 39-55). Tanto en el análisis de Kruskal-Wallis como en el de la U de Mann y Whitney; en el de ji-cuadrado y comparación entre dos proporciones se fijó previamente al 5\% como nivel de significación.

La extracción de la información de la base de datos se realizó mediante el cruce de variables, con tablas de contingencia y el uso de la opción partición del paquete estadístico InfoSTat versión 2019 de Di Rienzo y colaboradores (Balzarini et al., 2019). En caso de estar incompleta la información en alguna de las variables cruzadas, esa información faltante afectó inmediatamente el tamaño de la muestra, lo cual es consecuencia de que los avisos de prensa varían en su contenido informativo. Las informaciones faltantes afectaron tanto variables cuantitativas (por ejemplo, la edad), como variables cualitativas (por ejemplo, el sexo). 
Para los gráficos recurrimos al paquete estadístico Minitab (versión 2010).

\section{Resultados}

TABLA 1. Estadísticas descriptivas de la cantidad de esclavos comercializados durante el lapso 18271832

\begin{tabular}{llllllllll}
\hline Transacción & Variable & N & Media & DE & CV & Minimo & Máximo & Mediana \\
\hline Alquiler & CANTIDAD & 13 & 2,69 & 2,87 & 106,56 & 1,00 & 10,00 & 1,00 \\
\hline Compra & CANTIDAD & 104 & 1,39 & 1,46 & 104,55 & 1,00 & 10,00 & 1,00 \\
\hline Venta & CANTIDAD & 132 & 1,10 & 0,43 & 38,74 & 1,00 & 4,00 & 1,00 \\
\hline $\begin{array}{l}\text { Sin informa- } \\
\text { cón de compra }\end{array}$ & CANTIDAD & 0 & & & & & & \\
\hline $\begin{array}{l}\text { Sin informa- } \\
\text { ción de venta }\end{array}$ & CANTIDAD & 1 & & & & & & & \\
\hline $\begin{array}{l}\text { Total de avisos } \\
\text { utilizados }\end{array}$ & CANTIDAD & 249 & & & & & & & \\
\hline
\end{tabular}

\begin{tabular}{llllllllllll}
\hline $\mathrm{f}$ & Alquiler & CANTIDAD & 4 & 2,25 & 2,50 & 111,11 & 1,00 & 6,00 & 1,00 \\
\hline $\mathrm{f}$ & Compra & CANTIDAD & 67 & 1,01 & 0,12 & 12,04 & 1,00 & 2,00 & 1,00 \\
\hline $\mathrm{f}$ & Venta & CANTIDAD & 81 & 1,04 & 0,19 & 18,32 & 1,00 & 2,00 & 1,00 \\
\hline $\mathrm{m}$ & Alquiler & CANTIDAD & 9 & 2,89 & 3,14 & 108,70 & 1,00 & 10,00 & 1,00 \\
\hline $\mathrm{m}$ & Compra & CANTIDAD & 37 & 2,08 & 2,30 & 110,61 & 1,00 & 10,00 & 1,00 \\
\hline $\mathrm{m}$ & Venta & CANTIDAD & 50 & 1,18 & 0,63 & 53,30 & 1,00 & 4,00 & 1,00 \\
\hline $\mathrm{n}$ & número de registros & & & & & & \\
\hline \multicolumn{7}{l}{\begin{tabular}{l} 
Sin información \\
\hline
\end{tabular}} \\
\hline
\end{tabular}

Leyendas de las estadísticas descriptivas

$\mathrm{N}$ : número de datos, DE: desviación estándar, CV: compraventa

Resultados: entre 1827 y 1832 se publicaron en total en el Mercurio Peruano 249 avisos de prensa para ofertar esclavos en alquiler, compra o venta, de los cuales 13 avisos $(13 \times 2,69=35$ esclavos) eran de alquiler, $104(104 \times 1,39=144$ esclavos $)$ eran de compra y $132(132 \times 1,10=145$ esclavos) eran de venta, lo que da un total de 324 esclavos ofertados en 249 avisos. Estas cifras se obtienen de multiplicar el número de avisos de comercialización por el número promedio de esclavos ofertados. La cantidad de esclavos ofrecidos en alquiler y en compra osciló entre 1 y 10 y en venta entre 1 y 4. 
Al discriminar los esclavos ofertados por sexo, la información faltante fue de un caso y el total de avisos es de 248.

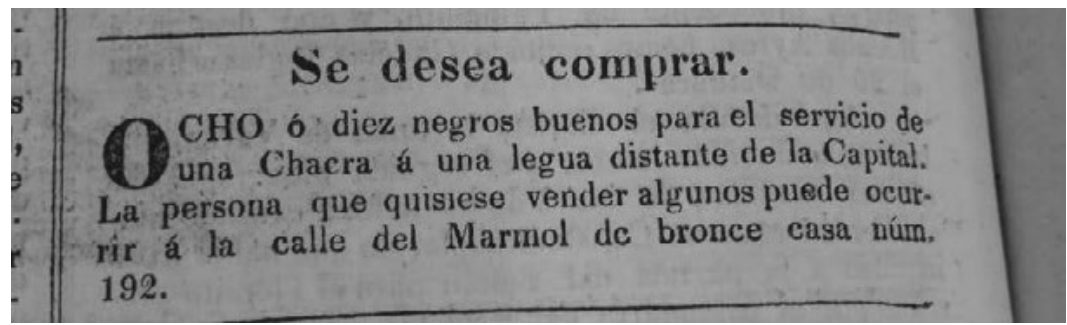

FIGURA 3. Aviso de compra de esclavos

Nota. Tomado de "Se desea comprar». (19 de agosto de 1831). Mercurio Peruano, 4781, p. 4.

TABLA 2. Comparación (análisis de varianza de Kruskal-Wallis) entre las cantidades de esclavos alquilados, comprados o vendidos (1827-1832)

\begin{tabular}{|c|c|c|c|c|c|c|c|c|}
\hline \multicolumn{9}{|c|}{ Número de operaciones por rubro durante 5 años totalizadas por 12 meses } \\
\hline Variable & Operación & $\mathbb{N}$ & Media & Mediana & Promedio Rangos & $g \mid$ & н & p \\
\hline CANTIDAD & Alquiler & 12 & 2,92 & 1,50 & 8,6 & 2 & 15,87 & 0,0008 \\
\hline CANTIDAD & Compra & 12 & 12,08 & 10,50 & 24 & & & \\
\hline CANTIDAD & Venta & 12 & 11,91 & 10,00 & 22,9 & & & \\
\hline \multicolumn{9}{|c|}{ Prueba de la máxima diferencia significativa } \\
\hline Operación & Rangos & & & & & & & \\
\hline Alquiler & 8,63 & A & & & & & & \\
\hline Venta & 22,92 & B & & & & & & \\
\hline Compra & 23,96 & $B$ & & & & & & \\
\hline
\end{tabular}

Letras distintas indican diferencias significativas $(p<=0,05)$

Resultado: el análisis de varianza de Kruskal-Wallis mostró la existencia de diferencias estadísticamente significativas entre las cantidades de esclavos comercializados $(H=15,87 \mathrm{p}<0,05)$ y la prueba de la mínima diferencia significativa evidenció la existencia de dos grupos, uno con la menor cantidad ( $\mathrm{A}=$ alquiler), $\mathrm{y}$ los grupos de venta y compra, identificados ambos con la letra B, lo cual es indicativo de la no existencia de diferencias estadísticamente significativas entre ellos, es decir, que las cantidades de esclavos ofrecidos en venta o en compra durante el lapso entre 1827 y 1832 fueron similares entre ellas, pero superiores a las ofrecidos en alquiler. Esto se ve claramente reflejado en la figura 4. 


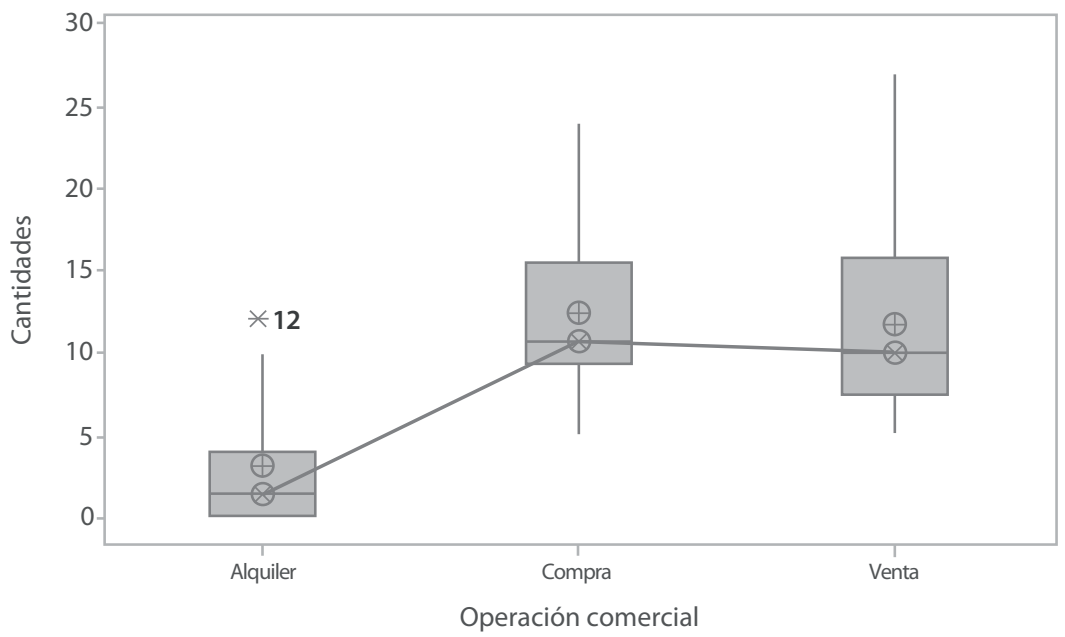

FIGURA 4. Comparación entre las cantidades de esclavos ofrecidos en alquiler, compra o venta (18271832)

TABLA 3. Comparación entre las cantidades de esclavos ofrecidos en comercialización discriminados por sexo (prueba de ji-cuadrado)

\begin{tabular}{|c|c|c|c|c|}
\hline & cuencias. & Id de esc & rcializz & \\
\hline & & & & \\
\hline Sexo & Alquiler & Compra & Venta & Total \\
\hline Femenino & 9 & 68 & 84 & 161 \\
\hline Masculino & 26 & 77 & 59 & 162 \\
\hline Total & 35 & 145 & 143 & 323 \\
\hline Estadísti & & Valor & gl & p \\
\hline Chi Cuadra & & 13,18 & 2 & 0,0014 \\
\hline
\end{tabular}

$\mathrm{N}=323 ; \mathrm{gl}=$ grados de libertad

Sin información: 2 registros

\begin{tabular}{|c|c|c|c|c|c|}
\hline \multicolumn{6}{|c|}{ Resultados prueba de comparación de proporciones } \\
\hline Transacción & $\begin{array}{c}\text { Porcentaje } \\
\text { Sexo masculino }\end{array}$ & $\begin{array}{l}\text { Porcentaje } \\
\text { Sexo femenino }\end{array}$ & Diferencia & Probabilidad & Significación \\
\hline Alquiler & $16 \%$ & $5,59 \%$ & $10,46 \%$ & $0,003<0,05$ & $S$ \\
\hline Compra & $47,5 \%$ & $42,2 \%$ & $5,3 \%$ & $0,37>0,05$ & N.S. \\
\hline venta & $36,42 \%$ & $52,17 \%$ & $15,7 \%$ & $0,005<0,05$ & $S$ \\
\hline
\end{tabular}

$S=$ significativa

N. S. $=$ no significativa 
Resultados: al considerar la cantidad de esclavos ofrecidos en comercialización, discriminados por sexo, el estadístico de prueba del análisis de ji-cuadrado $\left(X^{2}=13,18 p<0,05\right)$ indica la existencia de diferencias estadísticamente significativas. En vista de este resultado se procedió a la separación de los porcentajes correspondientes a cada operación en relación con el sexo, mediante la prueba de comparación de proporciones. Se encontró que el alquiler se asoció con esclavos de sexo masculino. No se observaron diferencias estadísticamente significativas en las compras, pero las ventas se asociaron con el sexo femenino.

\section{Comparación entre las edades de los esclavos ofrecidos en comercialización discriminados por sexo}

La comparación entre las edades se realizó mediante la prueba noparamétrica de la $U$ de Mann y Whitney, en vista de la presencia de valores anómalos, y se fijó como nivel de significación el 5\%. La representación gráfica de dicha comparación, se hizo con el gráfico de cajas (box plot). Para este análisis se contó con 102 edades (femenino $=60$; masculino $=42$ ).

TABLA 4. Estadísticas descriptivas de la edad de los esclavos ofrecidos en comercialización discriminados por sexo

\begin{tabular}{llllllll} 
Sero & N & Edad promedio & Mediana & Mínima & Máxima & Anómalos \\
\hline Femenino & 60 & 18,80 & 19,50 & 10 & 40 & $40-35$ \\
\hline Masculino & 42 & 16,07 & 14,00 & 1,00 & 38 & $35-38$ \\
\hline
\end{tabular}

Resultado: la edad de las esclavas (media $=18,80 ;$ mediana $=19,50$ ) ofrecidas en comercialización resultó superior a la de los esclavos (media $=16,07$; mediana $=14,00$ ), como lo evidenció el valor del estadístico de prueba de la $U$ de Mann y Whitney $(\mathrm{W}=1774)$, con una probabilidad inferior al $5 \%(p<0,05)$. Tanto en el caso de las esclavas como de los esclavos, se detectó la existencia de valores anómalos o valores no comunes, que en ambos casos se correspondió con edades de comercialización superiores a los 35 años.

\section{Comparación entre la edad de los esclavos ofertados, discrimi- nados por la operación comercial}

La comparación entre la edad de compra y/o venta de los esclavos se realizó mediante la prueba $U$ de Mann y Whitney, y se fijó como nivel de significación el $5 \%$. 


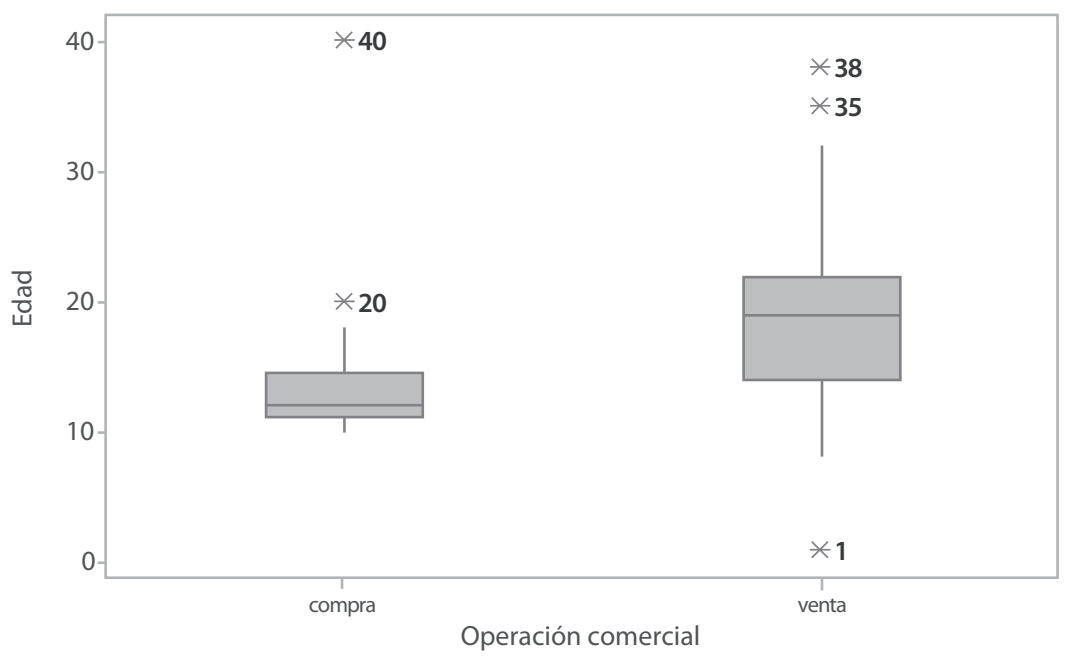

FIGURA 5. Comparación entre las edades de los esclavos en relación con la operación comercial

Resultados: los estadísticos de tendencia central (media y mediana), para las edades en relación con la operación comercial de la operación de compra $(n=21)$, fueron de 14,52 años y de 12 años, respectivamente, mientras que para la venta $(n=80)$ dichos estadísticos fueron los siguientes: la de 18,6 años para la media y de 19 años para la mediana. El valor del estadístico de prueba $W=672(p<0,05)$ nos indica la existencia de diferencias estadísticamente significativas entre las edades de las personas comercializadas, que son superiores en las ventas. En el proceso de compra los valores anómalos están representados por edades mayores a los 20 años, mientras que en las ventas dichos valores son de 35 años o más.

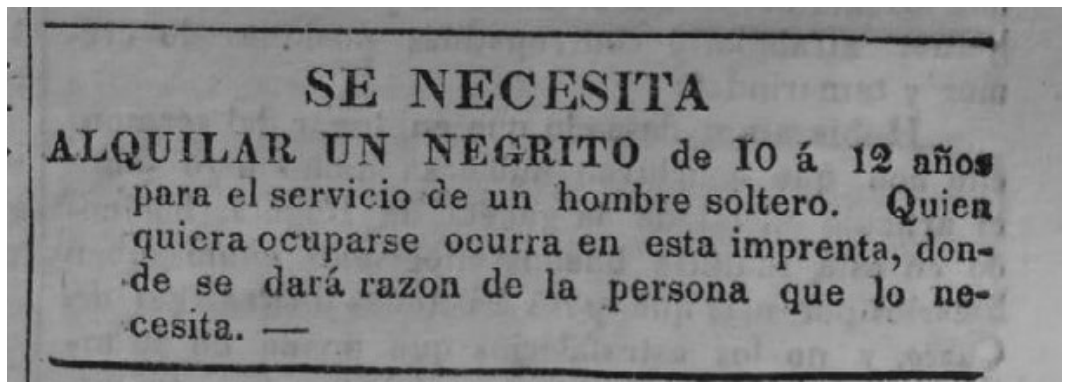

FIGURA 6. Aviso de alquiler de esclavo

Nota. Tomado de «Se necesita». (14 de setiembre de 1827). Mercurio Peruano, 36, p. 4. 


\section{Relación entre edad y operación comercial con el sexo de los esclavos}

La comparación entre la edad de compraventa de esclavos discriminados por sexo se evaluó mediante la prueba $U$ de Mann y Whitney, y los resultados fueron representados gráficamente mediante un diagrama de barras.

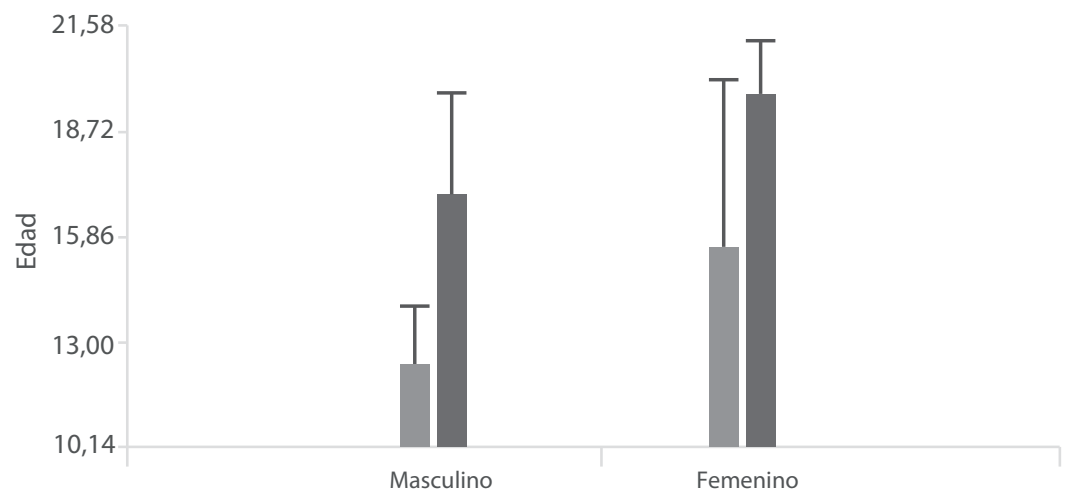

FIGURA 7. Edad promedio de comercialización de esclavos en relación con el sexo (prueba U de Mann y Whitney)

Compra $=$ gris

Venta $=$ plomo

Resultado: en la operación de compra, para el sexo femenino $(n=14)$, la media y la mediana fueron de 15,64 y 13 años de edad, respectivamente, y para los hombres $(n=7)$, la media fue de 12,29 años y la mediana de 20 , el valor del estadístico de prueba de $\mathrm{U}$ de Mann y Whitney fue $\mathrm{W}=65$ $(p>0,05)$, lo que indica que no existen diferencias estadísticamente significativas para esta operación comercial en relación con el sexo. En lo referente a las ofertas de ventas, para el sexo femenino $(n=46)$, la media y la mediana fueron de 19,76 años y 20 años, mientras que para el sexo masculino $(n=34)$ la media fue de 17,03 años y la mediana de 15,50 , con un valor del estadístico de prueba de la $\mathrm{U}$ de Mann y Whitney $\mathrm{W}=1128$ $(p<0,05)$. Esto nos indica que la venta de las mujeres ocurre a una edad mayor a la de los hombres.

\section{Comparación entre el precio de los esclavos discriminados por el sexo}

En los avisos de prensa del Mercurio Peruano durante el lapso revisado (1827-1832) solo se suministraron precios de comercialización en 31 casos, de los cuales 22 fueron de sexo femenino y 9 de sexo masculino. La prueba estadística empleada fue la $U$ de Mann y Whitney y se fijó previamente el 5\% como nivel de significación. El resultado fue 
representado gráficamente mediante el diagrama de cajas. La caja del sexo masculino es más pequeña porque su tamaño está en proporción al número de datos.

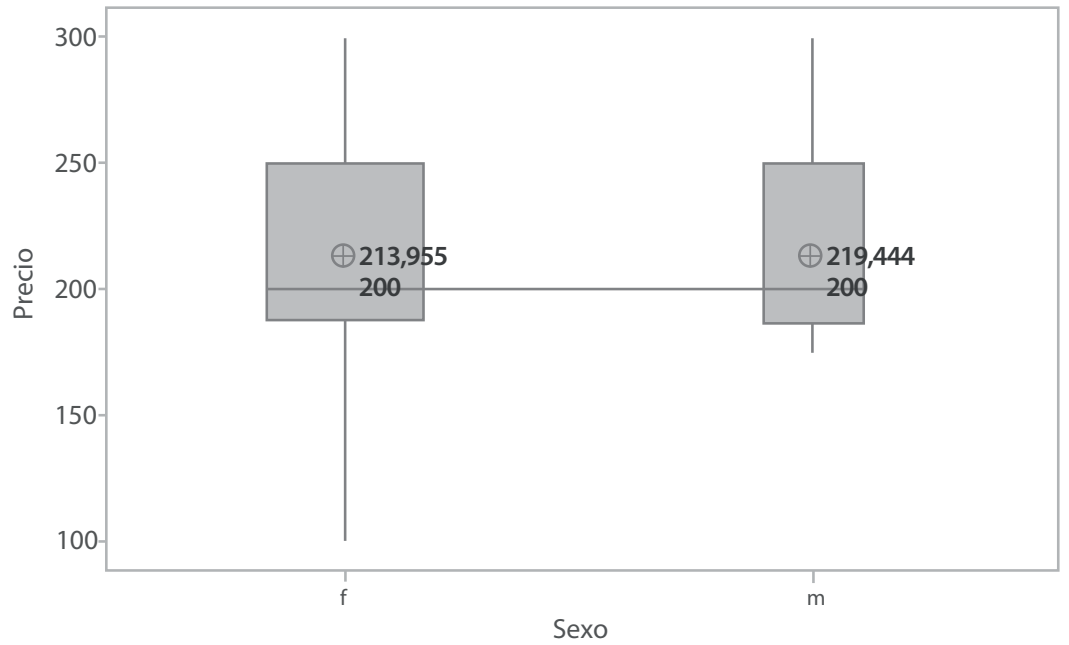

FIGURA 8. Comparación del precio de los esclavos según el sexo

TABLA 5. Estadísticas descriptivas de los precios de los esclavos (1827-1832)

\begin{tabular}{lcccccccccc|c}
\hline Variable & Sero & N & Media & DE & Minimo & Q1 & Mediana & QB & Máximo \\
PRECI0 & F & 22 & 213,9 & 54,6 & 100,0 & 188,0 & 200,0 & 250,0 & 300 \\
\cline { 2 - 11 } & M & 9 & 219,4 & 41,0 & 175,0 & 187,5 & 200,0 & 250,0 & 300 \\
\hline
\end{tabular}

Leyendas de las estadísticas descriptivas

F: femenino, M: masculino, N: número de datos, DE: desviación estándar, Q1: primer cuartil, Q3: tercer cuartil

Resultados: la media del precio de las esclavas fue de 213,95 y la de los esclavos de 219,44, mientras que las medianas resultaron iguales (200). La prueba estadística de comparación de medianas entre dos grupos ( $U$ de Mann y Whitney) indicó que entre los precios de los esclavos de acuerdo con el sexo ( $f=$ femenino, $m=$ masculino) no existían diferencias estadísticamente significativas ( $W=148 p>0,05$ ), lo que refleja una cotización similar en el mercado.

La información contenida en las estadísticas descriptivas nos muestra el precio máximo para un $25 \%$ de las transacciones (Q1) y el correspondiente al 75\% (Q3), mientras que el valor central o pivote fue de 200 pesos para ambos sexos. 


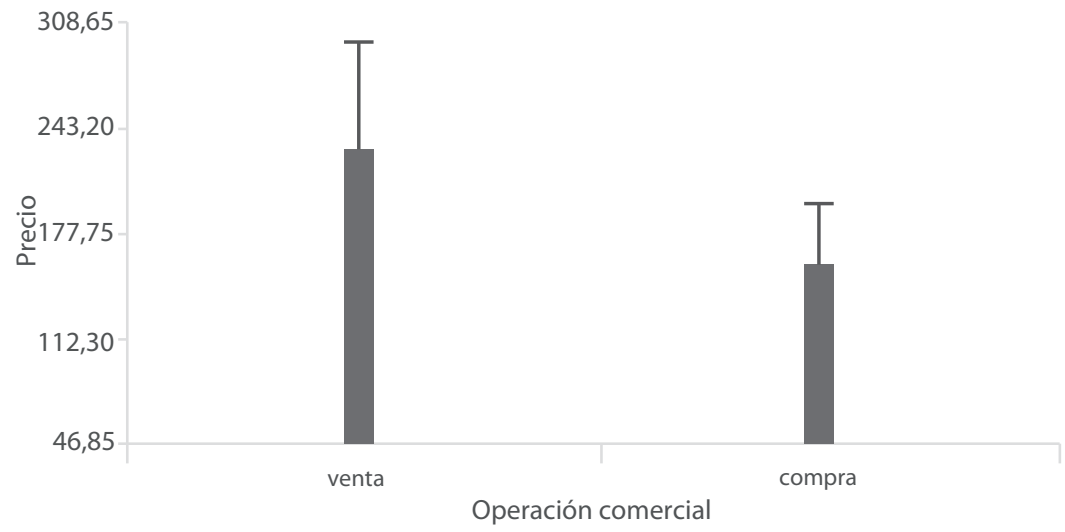

FIGURA 9. Comparación entre los precios de compra y venta de esclavos

Resultado: la prueba $U$ de Mann y Whitney arrojó diferencias estadísticamente significativas entre los precios ofertados de compra y venta de los esclavos ( $W=36 p<0,05)$. Los valores de la media $(158,33$ pesos) y la mediana (150 pesos) para la compra fueron muy inferiores a los precios correspondientes a las ventas (media $=229,28$ pesos y mediana $=$ 225 pesos) (figura 9). Para este análisis solo contamos con 31 datos (6 para la compra y 25 para la venta).

\section{Denominaciones usadas en los avisos de prensa del Mercurio Peruano (1827-1832) para la comercialización de esclavos}

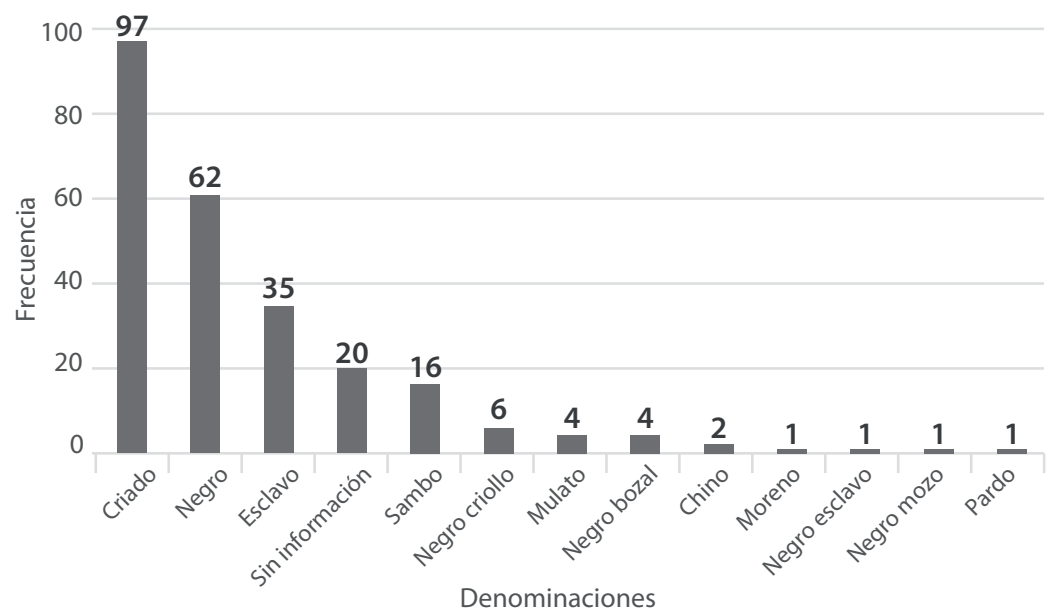

FIGURA 10. Denominaciones usadas en avisos de prensa en la comercialización de esclavos Nota. En la parte superior de cada barra se observa la frecuencia de casos observados. 
Resultado: el término más frecuentemente empleado fue criado (97/250), seguido de negro (62/250). Luego encontramos la denominación de esclavo (35/250) y la de sambo (16/250). El resto de denominaciones fueron utilizadas en dichos avisos con muy baja frecuencia.

\section{Frecuencia de la denominación de los esclavos para su comercialización en los avisos de prensa del Mercurio Peruano (1827-1832)}

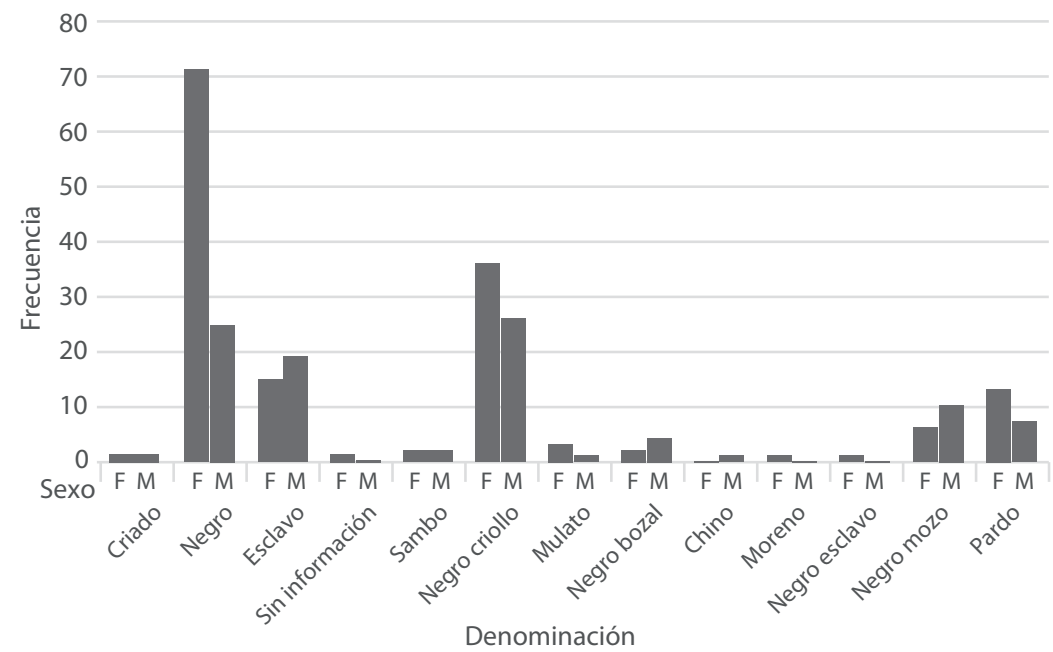

FIGURA 11. Frecuencia de las denominaciones según el sexo de los esclavos ofertados

Resultados: en la figura 11 vemos cómo las denominaciones mayormente utilizadas son las de criado, esclavo y negro. Corresponde la mayor frecuencia del término criado(a) y negro( $(a)$ a las mujeres; mientras que en el caso de los hombres el término esclavo es levemente superior con respecto a su empleo en las mujeres $y$, aunque con muy poco uso, el término sambo es también ligeramente superior en el caso de los hombres.

Resultados: los oficios laborales ofertados en los avisos de prensa publicados en el Mercurio Peruano (1827-1832) fueron mayoritariamente el de servicio, seguido del de chacra, cocinar y lavar, lactar y luego una gran variedad de oficios, pero con muy poca frecuencia. Es de notar que los avisos sin indicar el oficio del esclavo ofertado resultaron también mayoritarios (figura 12). 


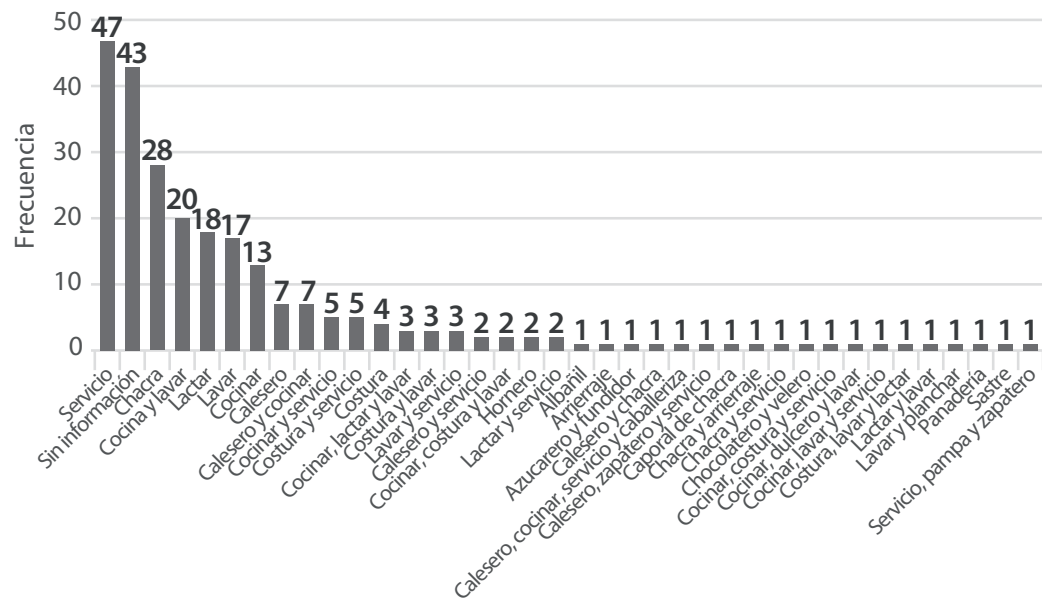

Oficios ofertados

FIGURA 12. Oficios ofertados en avisos de comercialización de esclavos

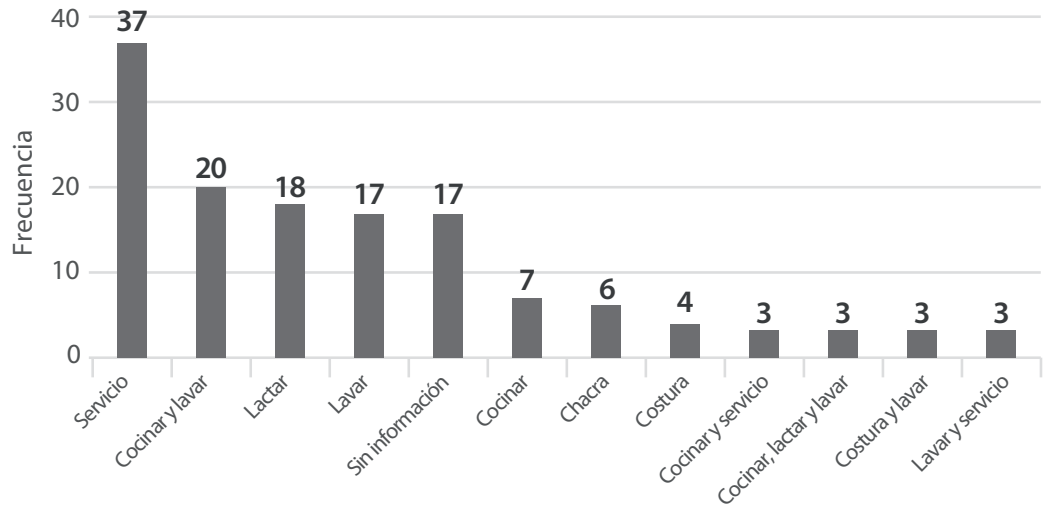

Oficios

FIGURA 13. Oficios más frecuentes de las esclavas comercializadas. Mercurio Peruano (1827-1832)

Resultados: entre los oficios más frecuentes de los que se anunciaban en los avisos para la comercialización de las esclavas destacan el de servicio, cocinar y lavar, lactar y lavar; los de menor frecuencia incluyeron chacra, costura, etc. (figura 13). 


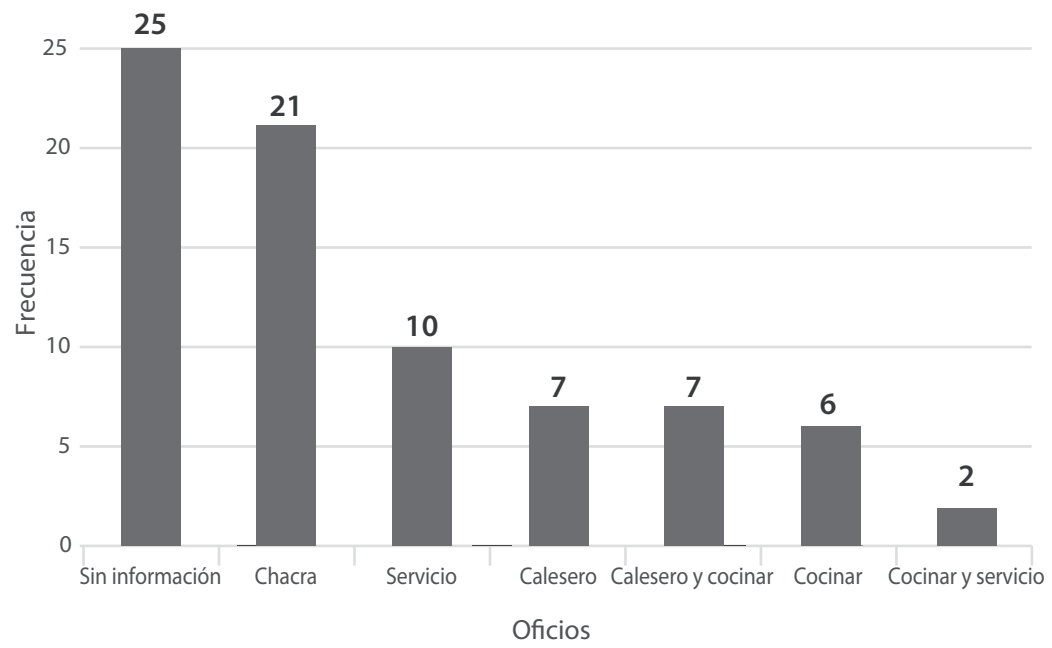

FIGURA 14. Oficios más frecuentes de los esclavos ofrecidos en comercialización. Mercurio Peruano (1827-1832)

Resultados: en esta figura destaca que la ausencia de información en torno al oficio ocupará la frecuencia más elevada. El trabajo agrícola o de chacra, el servicio y el oficio de calesero eran los más relacionados con los esclavos varones (figura 14).

\section{Conclusiones}

El mercado de esclavos representado en los avisos del Mercurio Peruano (1827-1832) refleja un proceso bastante complejo, con marcada influencia de la edad y el sexo y con variaciones de los precios ofertados incluso si se trataba de alquiler, compra o venta.

En Lima, después de la independencia, no hubo casi esclavos bozales en el mercado. La amplia mayoría de los ofertados y demandados eran esclavos criollos y sus precios nominales descendieron significativamente. La media del precio (ofertas de venta y ofertas de compra) de las esclavas fue de 213,95 pesos y la de los esclavos fue de 219,44 pesos.

El aviso comercial de esclavos es una unidad discursiva que a veces incluía elementos gráficos, propios de la tipografía internacional. En algunos casos, constituyen micronarraciones de la vida de los esclavizados (edad, sexo, competencias laborales, procedencia regional, origen étnico). Existe una diferencia importante en la configuración discursiva del esclavo; cuando se busca un esclavo fugado o perdido, los esfuerzos de descripción son más detallados e incluyen aspectos negativos asociados al cuerpo mismo (cicatrices, enfermedades, discapacidades), a diferencia 
de cuando se quiere vender (se destaca que son sanos y robustos) o comprar uno (se exige que sean sanos, jóvenes, ágiles, limpios).

La oferta de esclavos en compra o venta resultaron similares entre sí, pero superiores a la de alquiler. El sexo masculino se asoció con la oferta comercial de alquiler y la de venta con el sexo femenino, mientras que la oferta de compra arrojó resultados similares.

Las edades promedio en las ofertas de comercialización fueron en hombres, 16,07 años y en mujeres, 18,8 años; en ambos casos inferiores a 20 años. Sin embargo, corresponde a las mujeres una edad promedio de venta superior a la de los varones. En el proceso de compra, los valores anómalos están representados por edades mayores a los 20 años, mientras que en las ventas dichos valores son de 35 años o más. Un esclavo de edad avanzada costaba ya muy poco dinero; hay un caso en que se ofrece a una famosa cocinera, entre 40 y 50 años, por solamente 100 pesos.

El sexo del esclavo no marcó diferencia en el precio de comercialización; corresponde a ambos sexos una mediana de 200 pesos. Sin embargo, los precios de la oferta de venta en los avisos comerciales resultaron superiores a los precios de la oferta de compra.

En cuanto a las denominaciones, las más frecuentes fueron las de criado, negro, esclavo y sambo. Todas hacían referencia a esclavos no-bozales o criollos (nacidos en tierras americanas). Se valoraba más económicamente a un esclavo negro que a un esclavo sambo.

Los oficios ofertados en el caso de las mujeres eran los de servicio, cocinar, lavar y lactar. En los hombres, estaban en primer lugar el trabajo agrícola o de chacra, servicio y el de calesero. Sin embargo, se encuentra un pequeño número de esclavos especializados, principalmente en el rubro de la cocina (hornero, dulcero, chocolatero) y la costura, que tenían un precio de venta muy superior al promedio.

La sostenida presencia de avisos comerciales de esclavos en la prensa republicana, en la misma sección donde se ofertaban otras mercancías y servicios, presupone que el mercado de esclavos constituía parte de la experiencia cotidiana de los lectores y su sociedad. Así se confirma que la visión hegemónica no veía contradicción entre los discursos políticos republicanos que discutían los principios de libertad y voluntad del pueblo, y la dinámica de la esclavitud que comerciaba con hombres, percibidos como propiedad de otras personas.

\section{Discusión}

Jonathan Prude (1991) sostiene que los avisos de fuga de esclavos en Estados Unidos entre 1750 y 1800 se engarzan con el fortalecimiento de 
una cultura visual que coloca en el más alto sitial la observación y la descripción. Los sectores populares no merecían mayor atención en las formas canónicas de representación de las élites, pero en estos avisos ellos ocupan el centro de la representación. Esta perspectiva queda ampliada en esta investigación, pues los avisos de esclavos — no solo los de fugaposibilitan un acceso a las retóricas de la descripción del esclavo mismo y de sus habilidades laborales. En el caso de las fugas, efectivamente, la descripción del cuerpo mismo se privilegiaba. Por todo ello, el aviso de esclavos constituye una unidad discursiva que contiene fragmentos de la vida del esclavizado y la lógica del mercado de esclavos.

Este artículo es el primero en analizar un amplio corpus de avisos del mercado de esclavos en Lima. De los 249 avisos del Mercurio Peruano, la amplia mayoría de esclavos que se anuncian son no-bozales o criollos. En contraste, solamente hay cuatro esclavos que se anuncian expresamente como «bozales». Por otro lado, la media del precio de las esclavas fue de 213,95 pesos y la de los esclavos fue de 219,44 pesos. Estas cifras marcan un abrupto descenso en comparación con las encontradas por Haro entre 1800 y 1819 (2017, pp. 71-72). Un descenso aproximado en los precios nominales de $28,5 \%$ menos para los varones no-bozales y de $36,4 \%$ menos para las mujeres no-bozales.

En la historiografía sobre la esclavitud se menciona un descenso del precio de los esclavos en el mercado de Lima después de la Independencia, pero nunca se había establecido la magnitud de ese descenso. Nótese que la guerra de independencia no es un factor directo en este marcado descenso, pues, como se sabe, hasta 1820 la costa peruana no se vio afectada por la Expedición Libertadora y todo el proceso concluyó en 1824, antes del inicio de la publicación estudiada en este artículo.

Dentro del conjunto de esclavos criollos había también diferencias: si correlacionamos nominaciones con precios, se observa que los mayores precios corresponden a los esclavos «negros» sobre los esclavos «sambos». Esto indica una mayor preferencia y valoración de los esclavos no-mestizos. La explicación podría radicar en que se consideraba desde la experiencia que un esclavo con menos redes sociales y capacidad de interacción lingüística tenía menos posibilidades de huir o de buscar su libertad personal mediante la autocompra o pretender cambiar de amo mediante medios legales.

Tanto Velázquez (2013, p. 112) como Chocano coinciden en señalar la relevancia de la prensa en la esfera pública republicana y el efecto socavador del principio de la igualdad que tuvieron los avisos que comerciaban esclavos en ella y configuraban socialmente al esclavo, como mera mercancía en un mercado amplio de bienes y servicios. Chocano (2019, 
pp. 130-131), con ejemplos del propio Mercurio Peruano, analiza con precisión la tipografía de los símbolos gráficos, que representaban a los esclavos marcados por la errancia y la desposesión. Hay que añadir que estas convenciones gráficas de la cultura de lo escrito se empleaban en la prensa de muchos países, como Brasil y Estados Unidos. Sin duda, la publicación de numerosos avisos comerciales de esclavos en la prensa republicana consolidó la tipificación social entre el trabajo manual y la población negra de Lima, incluso después de la abolición de la esclavitud.

Por otro lado, nuestra investigación ofrece el mayor rango de oficios de los esclavos ofertados y demandados en Lima en función de la variable género. La crítica historiográfica ha insistido en la dualidad trabajador agrícola en el campo y servidor doméstico en la ciudad, como marco general desde los pioneros trabajos, como el de Carlos Aguirre en 1993 hasta los últimos de Chocano en 2019.

Aunque ya se conocían los principales oficios de los esclavos en las ciudades, esta investigación aporta novedades, como las especialidades de «albañil», «sastre», «chocolatero», «hornero», «dulcero», «zapatero»; o en el caso de las mujeres, «costurera», que no estaban identificadas en investigaciones anteriores. Esto nos permite postular que hubo un pequeño número de trabajadores especializados entre los varones y mujeres esclavas en Lima, muchos vinculados a servicios especializados, la cocina y la pastelería. La especialización laboral se correlacionaba con un precio de venta más alto; por ejemplo, un esclavo hornero o una esclava costurera se vendía a 300 pesos, muy por encima del promedio.

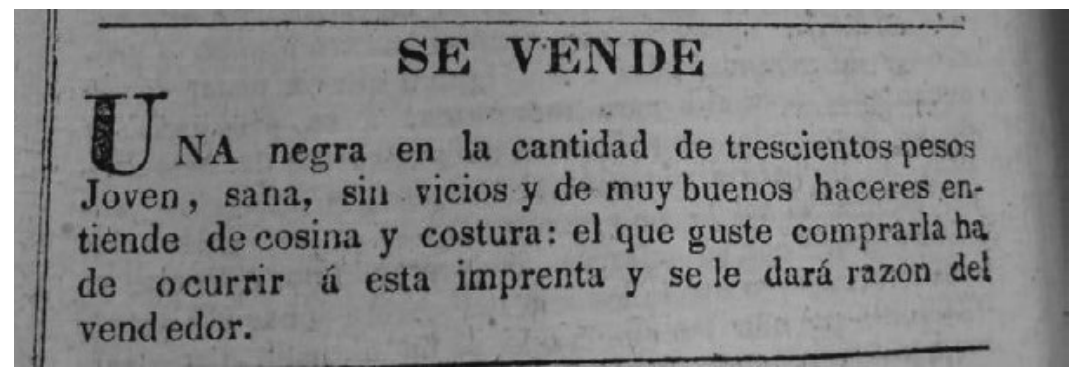

FIGURA 15. Anuncio de venta

Nota. Tomado de «Se vende». (27 de noviembre de 1828). Mercurio Peruano, 3881, p. 4. 


\section{SE VENDE}

T 1 esclavo hornero, de edad de 32 años, en 300 pesos, el que quiera comprarlo puede ocurrir á la Calle de Sn. Cristobal No. 149 Se necesitaruna criada en dicha casa.

FIGURA 16. Anuncio de venta

Nota. Tomado de «Se vende». (26 de julio de 1828). Mercurio Peruano, 2881, p. 4.

\section{Contribución de autoría}

Marcel Velázquez realizó el análisis histórico de la esclavitud y la interpretación discursiva de los avisos. Gustavo Morales hizo el análisis estadístico de los datos.

\section{Fuente de financiamiento}

Autofinanciado.

\section{Potenciales conflictos de interés}

Ninguno.

\section{REFERENCIAS BIBLIOGRÁFICAS}

Aguirre, C. (1993). Agentes de su propia libertad. Los esclavos de Lima y la desintegración de la esclavitud: 1821-1854. Pontificia Universidad Católica del Perú.

Basadre, J. (1983). Historia de la República del Perú. (7.a ed.). Editorial Universitaria.

Balzarini, M., González, L., Tablada, E., Casanoves, F., Di Rienzo, J. y Robledo, C. (2008). Infostat: manual del usuario. Editorial Brujas.

Balzarini, M., González, L., Tablada, E., Casanoves, F., Di Rienzo, J. y Robledo, C. (2019). InfOStat versión 2019. Centro de Transferencia InfOStat. Universidad Nacional de Córdoba. 
Chocano, M. (2019). Apuntes sobre la esclavitud y la trata de personas en los inicios del Perú republicano (1821-1855). Investigaciones Sociales, 22(41), pp. 121-137. https://doi.org/10.15381/is.v22i41.16782

Haro, V. (2017). Precio de los esclavos en el Perú: 1650-1820. [Tesis de licenciatura en Economía, Pontificia Universidad Católica del Perú]. https://tesis.pucp.edu.pe/repositorio/handle/20.500.12404/9151

Hünefeldt, C. (1994). Paying the price of freedom. University of California Press.

Lockhart, J. (1982). El mundo hispano-peruano 1532-1560. Fondo de Cultura Económica.

Mercurio Peruano. (1827-1833). Lima. Imprenta de J. M. Masías

Minitab INC. (2010). Data analysis and quality tools, release 17 for Windows adobe systems incorporated. Pennsylvania State College.

Morales, G. y Pino, L. (2009). Estadística no paramétrica aplicada a las ciencias de la salud. Universidad Católica Andrés Bello.

Porras, R. (1970). El periodismo en el Perú. Instituto Raúl Porras Barrenechea.

Prude, J. (junio de 1991). To look upon the «Lower Sort»: Runaway ads and the appearance of unfree laborers in America, 1750-1800. The Journal of American History, 78(1), pp. 124-159. https://doi.org/10.2307/2078091

Siegel, S. y Castellán, J. (1995). Estadística no paramétrica. Editorial Trillas.

Tardieu, J. (2004). El decreto de Huancayo. La abolición de la esclavitud en el Perú. Fondo Editorial del Congreso de la República del Perú.

Velázquez, M. (2005). Las máscaras de la representación. El sujeto esclavista y las rutas del racismo en el Perú (1775-1895). Fondo Editorial de la Universidad Nacional Mayor de San Marcos.

Velázquez, M. (2013). La mirada de los gallinazos. Cuerpo, fiesta y mercancía en el imaginario sobre Lima (1640-1895). Fondo Editorial del Congreso de la República del Perú. 